\title{
Home range size in central chimpanzees (Pan troglodytes troglodytes) from Loango National Park, Gabon
}

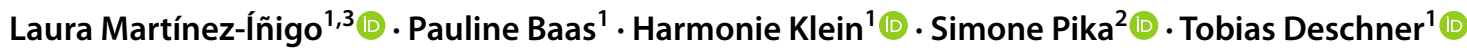

Received: 25 October 2020 / Accepted: 21 June 2021 / Published online: 4 July 2021

(c) The Author(s) 2021

\begin{abstract}
Ranging behavior has been studied extensively in eastern (Pan troglodytes schweinfurthii) and western (P. t. verus) chimpanzees, but relatively little is known regarding home ranges of the other two subspecies (P. t. ellioti; P. t. troglodytes). In this study, we determined the home range size and space use of a habituated community (Rekambo) of central chimpanzees living in a habitat mosaic in Loango National Park, Gabon. Data on travel routes were collected during follows between January 2017 and April 2019 ( $N=670,616$ relocations, collected over 640 days and $5690 \mathrm{~h}$ of observation). We used three methods for calculating home range size (minimum convex polygon, kernel density estimation, and biased random bridges). We compare our estimates to those obtained from prior genetic and camera trap studies of the Rekambo community and contrast them with estimates from other chimpanzee communities of the four chimpanzee subspecies. Depending on the methodology used, the home range size of the Rekambo community ranged between 27.64 and $59.03 \mathrm{~km}^{2}$. The location of the center of the home range remained relatively stable over the last decade, while the overall size decreased. The Rekambo home range is, therefore, one of the largest documented so far for chimpanzees outside savannah-woodland habitats. We discuss several explanations, including the presence of savannah, interspecies competition, and intercommunity interactions.
\end{abstract}

Keywords Territory $\cdot \mathrm{BRB} \cdot$ Interspecies competition $\cdot$ Intercommunity competition $\cdot$ Habitat mosaic

\section{Introduction}

Animals usually restrict their activities to particular areas which may range from a few square meters to thousands of square kilometers (Burt 1943; Laver and Kelly 2008; Powell and Mitchell 2012). Such areas are called home ranges and are the specific geographic regions that an animal or a group of animals uses to meet its needs over a defined time span (Burt 1943). By comparing home range sizes across

Laura Martínez-Íñigo and Pauline Baas are joint first authors.

Laura Martínez-Íñigo

laura_m_innigo@live.com

1 Interim Group Primatology, Max Planck Institute for Evolutionary Anthropology, Deutscher Platz 6, 04103 Leipzig, Germany

2 Institute of Cognitive Science, Comparative BioCognition, Osnabrück University, Artilleriestrasse 34, 49076 Osnabrück, Germany

3 Wild Chimpanzee Foundation - Guinean Representation, Commune de Dixinn, BP1487P Conakry, Guinea populations, it is possible to understand the ecological flexibility of species. Estimating home ranges sheds light on what habitats are essential for a species and how it might respond to environmental change (Mitani et al. 2010; Cumming and Cornélis 2012; Powell and Mitchell 2012; Fieberg and Börger 2012). As such, home range estimations are essential for understanding species-specific ecological requirements and implementing management and conservation programs (Fauvelle et al. 2017; Albani et al. 2020).

Chimpanzees (Pan troglodytes) are an endangered species with four subspecies: eastern (P. t. schweinfurthii), western ( $P$. t. verus), Nigeria-Cameroon (P. t. ellioti), and central chimpanzees (P. t. troglodytes) (Humle et al. 2016). Chimpanzees live in communities comprising multiple adult males and females and their offspring (Nishida 1979; Goodall 1986; Boesch and Boesch-Achermann 2000; Watts and Mitani 2015). Across chimpanzee communities and subspecies, individuals spend most of their time in smaller parties (i.e., subgroups) of varying size and composition, termed fission-fusion societies (Nishida 1979; Goodall 1986; Boesch and Boesch-Achermann 2000; Watts and Mitani 2015). Activities are restricted to a home 
range whose location is relatively stable across the years, although its shape and size can vary relatively widely over time (Nakamura et al. 2013). Chimpanzees defend their home ranges aggressively and often lethally from neighboring communities (Mitani et al. 2010; Lemoine et al. 2020). Thus, chimpanzee home ranges are commonly called territories. They contain a heavily used central area (i.e., core area) surrounded by a less frequently visited periphery that may overlap extensively with neighboring territories (Herbinger et al. 2001; Wilson et al. 2001). Home range size in chimpanzees is related to the size of the community, food availability, population density, intercommunity relationships, and interspecific competition (Nishida et al. 1985; Goodall 1986; Boesch and Boesch-Achermann 2000; Herbinger et al. 2001; Lehmann and Boesch 2003; Amsler 2009; Mitani et al. 2010; Head et al. 2012; Nakamura et al. 2013; Lemoine et al. 2020).

Ranging patterns have been predominantly studied in eastern and western chimpanzees (see references above). However, relatively little is known about Nigeria-Cameroon chimpanzees and central chimpanzees (see for an overview Table S1 in Electronic Supplementary Material, ESM, and Abwe 2018). Central chimpanzees have been studied in a relatively homogenous forested environment (Morgan et al. 2006). Nevertheless, some communities, such as the Rekambo community in Loango National Park in Gabon, live in a mosaic of different habitats that contains savannahs and mangroves in addition to forests and swamps (Boesch et al. 2007). Loango National Park harbors a high density of two main food competitors, forest elephants (Loxodonta cyclotis) and western lowland gorillas (Gorilla gorilla gorilla) (Head et al. 2011, 2012, 2013).

Previous studies showed that the Rekambo community was surrounded by 3-5 other chimpanzee communities (Arandjelovic et al. 2011; Head et al. 2013). Before the habituation of the Rekambo community, their minimum home range was estimated as $45 \mathrm{~km}^{2}$, using noninvasive genetic monitoring (Arandjelovic et al. 2011), and 24.4 $\mathrm{km}^{2}$ using camera traps (Head et al. 2013). Preliminary direct observational data led to a home range estimate of $36 \mathrm{~km}^{2}$ for the community (Head et al. 2013). Here, we provide the first estimates of the home range of the Rekambo community based on data collected when most individuals were fully habituated to human presence, enabling direct and regular behavioral observations. We calculated annual and cumulative home ranges from January 2017 to April 2019, using three different estimators: minimum convex polygon, kernel density estimates and biased random bridges. Minimum convex polygon (Mohr 1947) and kernel density estimation (Worton 1987) have been commonly used to estimate chimpanzee home ranges (see Table S1 in ESM). Consequently, these estimators are useful for comparing estimates across chimpanzee sites. The third estimator, biased random bridges (Benhamou and Cornélis 2010), is more suited for the data that we have available than the more traditional estimators. We then compare our estimates to the minimum home range estimates of studies on the Rekambo community prior to their habituation (Arandjelovic et al. 2011; Head et al. 2013), as well as to estimates of other chimpanzee communities, and discuss the potential drivers of our results.

\section{Methods}

\section{Study site and community}

The study site was established in 2005 in Loango National Park, Gabon (see Fig. 1, $2^{\circ} 04^{\prime} \mathrm{S}, 9^{\circ} 33^{\prime} \mathrm{E}$; Boesch et al. 2007). The area consists of a mosaic of rivers, swamps, coastal forests, mangroves, savannahs, and secondary and mature forests, bordered by the Atlantic Ocean and a lagoon (Boesch et al. 2007). The mean annual rainfall in 2017-2018 was $2099 \mathrm{~mm}$. Temperatures ranged between 18 and $32{ }^{\circ} \mathrm{C}$ across the same period, with the mean minimum and maximum temperatures being $22.7^{\circ} \mathrm{C}$ and $27.8{ }^{\circ} \mathrm{C}$, respectively. There is a long rainy season between October and April, interrupted by a short dry season between December and January. The long dry season usually lasts from May to September (Head et al. 2011).

The size of the Rekambo community ranged from 44 to 47 individuals during the study period, including 16-17 adult females and 8-9 adult males (see Table S2 in ESM).

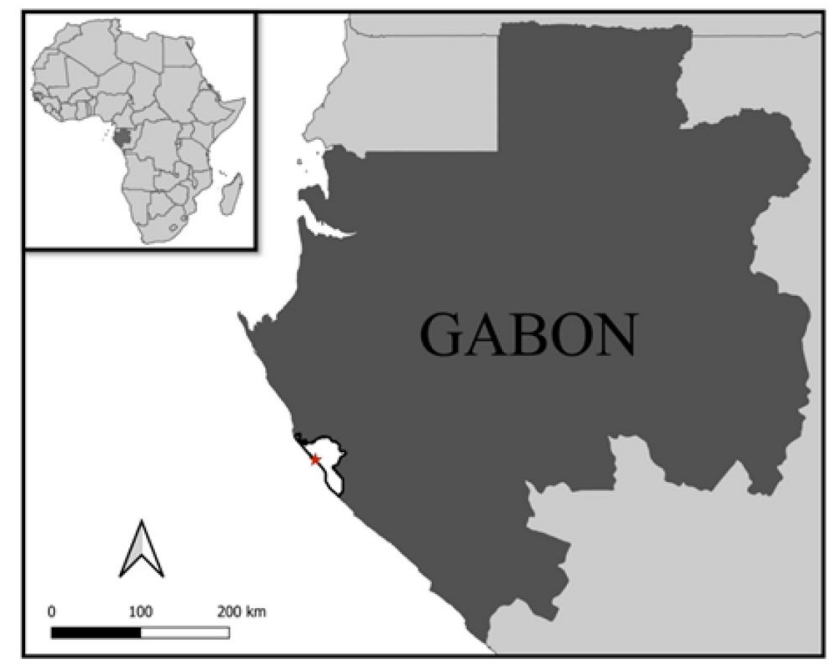

Fig. 1 Location of study site (red star) in Loango National Park (white), Gabon (dark gray). Maps were created using QGIS (v.3.10.5, QGIS Development Team, 2019), and shapefiles from the Map Library (Map Maker Ltd 2007) and Protected Planet (UNEP-WCMC and IUCN 2020) 


\section{Data collection and preparation}

Between January 2017 and April 2019, observers followed parties of chimpanzees of the Rekambo community as soon as they encountered them each day. Similarly to all other communities studied so far, the entire community is rarely found together. Instead, individuals move alone, in a single party, or switch between several different parties over the course of a day. Observers followed the largest possible party of chimpanzees throughout the contact rather than particular individuals. Thus, the followed party may change size and composition throughout a given contact. Whenever possible, different teams of observers followed more than one party simultaneously. A contact started when observers saw at least one member of the community (contact starting time: median: 6:50, min: 6:00; max: 16:50). Observers stopped a contact before dusk or when no member of the community had been observed for more than $30 \mathrm{~min}$ (contact ending time: median: 17:55, min: 7:31; max: 18:55). Track$\log$ data were collected every 1-60 s using a handheld GPS device (Garmin, Rhino 750) and downloaded into BaseCamp software (v. 4.7.1. Garmin Ltd. 2008). Whenever information from simultaneous contacts was available (i.e., traveling routes of different parties recorded over the same period by different teams of observers), only the longest duration travel route was retained for downstream analyses. This exclusion was necessary because the biased random bridges estimator cannot be computed with simultaneous routes belonging to the same individual or group. We applied the exclusion to the calculation of the three estimators to allow an easier comparison between their results.

\section{Home range analysis}

We used a total of 670,616 relocations collected over 640 days and $5691 \mathrm{~h}$ of observation to calculate the home range of the Rekambo community from January 2017 to April 2019 (mean \pm SD; $1126 \pm 547$ relocations/day). We calculated the home range using three estimators: minimum convex polygon (MCP), kernel density estimation (KDE), and biased random bridges (BRB) (for details see ESM).

MCPs are obtained by joining the outermost relocations to create a polygon with all internal angles not exceeding 180 degrees and encompassing all recorded locations. KDE calculates the probability of finding the target animal or group at any given time based on the frequency of having identified the target at the location and its nearby surroundings in the past (Powell and Mitchell 2012). BRB is an extension of $\mathrm{KDE}$ specifically designed to address movement data autocorrelation without the need for subsampling (Benhamou and Cornélis 2010). BRB incorporates information regarding the order in which locations are obtained, the time lag between them, as well as the average error made when locations are recorded (Benhamou and Cornélis 2010). The technique interpolates inferred locations in a straight line between each pair of consecutively recorded locations.

We computed and mapped the home ranges in $\mathrm{R}(\mathrm{v}$. 4.0.2, R Core Team 2020) using the package adehabitatHR (v0.4.18, Calenge 2006). We calculated home range size with MCP, KDE, and BRB using the isopleths $99 \%, 98 \%$, and $95 \%$ to provide comparable estimations to results from other habituated chimpanzee communities (see Table S1 in ESM). We calculated the 100\% isopleth only for MCP, which is the only method amenable to the procedure and has been widely used to calculate home range size in chimpanzees (see Table S1 in ESM). We estimated the core range area as $80 \%, 75 \%$, and $50 \%$ isopleths for comparability with other chimpanzee studies (see Table S1 in ESM).

We calculated fixed KDE using the $h_{\text {ref }}$ and $h_{\mathrm{LSCV}}$ techniques to select the smoothing parameter, since they have been used most often in other chimpanzee studies (Kouakou et al. 2011; Boyer Ontl 2017; Moore et al. 2018; Green et al. 2020a). However, our model did not converge with $h_{\mathrm{LSCV}}$. This is a frequent problem when the number of relocations is high (Walter et al. 2011; Pebsworth et al. 2012; Bauder et al. 2015; Boyer Ontl 2017; Moore et al. 2018). The value of $h_{\text {ref }}$ for the cumulative home range (i.e. January 2017-April 2019) was 155.6736.

We used the package adehabitatLT (v.0.3.25, Calenge 2006) to store the travel routes into a ltraj object, which is necessary to calculate BRB in adehabitatHR. The values of the parameters needed to estimate BRB and their justification can be found in the ESM.

We calculated annual home ranges for 2017 and 2018 respectively, using the three techniques described above. Data for 2017 included 205,545 relocations collected for 259 days ( $856 \pm 479$ relocations/day) and $2328 \mathrm{~h}$ of observation. Data for 2018 included 340,263 relocations collected for 277 days ( $1326 \pm 529$ relocations/day) and $2793 \mathrm{~h}$ of observation. For KDE, $h_{\text {ref }}$ of 2017 was 152.8558 , and $h_{\text {ref }}$ of 2018 was 172.765. All other parameters were the same for annual and cumulative estimates.

We used the package caTools (v.1.18.0, Tuszynski 2020) in $\mathrm{R}$ to calculate the area under the curve (AUC, Cumming and Cornélis 2012; Walter et al. 2015). AUC detects when a home range estimate includes areas in which there is no evidence of the presence of the target and excludes areas in which there is evidence of presence (Cumming and Cornélis 2012; Walter et al. 2015). Consequently, AUC serves as a goodness-of-fit metric, whose values range from 0.5 to 1 . The closer AUC is to 1 , the closer is the agreement between the estimated home range and the GPS relocations (Cumming and Cornélis 2012). We calculated AUC as in Cumming and Cornélis (2012, see R code in ESM); that is, we calculated one AUC per utilization density volume 
or $\mathrm{MCP}_{100}$ and not per isopleth. All estimates were made with grids of $100 \mathrm{~m} \times 100 \mathrm{~m}$ to allow for comparable AUC calculations.

\section{Recalculating MCP and KDE under different relocation subsampling regimes}

Commonly, chimpanzee home range size estimated by MCP and KDE use subsampling of 1-4 GPS relocations per observation day (Fawcett 2000; Newton-Fisher 2003; Morgan et al. 2006; Moore et al. 2018; Green et al. 2020a). Alternatively, subsampling relocations to one every 15-30 min is also employed (Herbinger et al. 2001; Williams et al. 2002; Amsler 2009; Kouakou et al. 2011; Wilson et al. 2012). Thus, to provide comparable estimates for the Rekambo community to other chimpanzee groups, we recalculated their home range between January 2017 and April 2019 under three subsampling regimes. We generated 30 subsets of data: ten subsets with one relocation per observation day $\left(N_{\text {relocations }}=640\right)$, ten subsets with three relocations per observation day $\left(N_{\text {relocations }}=1920\right)$, and ten subsets with twelve relocations per observation day $\left(N_{\text {relocations }}=7680\right.$; equivalent to 1-2 relocations per hour). Relocations were randomly selected per each observation day. We calculated MCPs (100\% and 50\%) and KDEs (95\% and 50\%), as described in the previous section, for each of the 30 subsets of data. We performed ANOVAs to investigate the differences between the average size of the home ranges estimated under the three subsampling schemes, depending on the technique and isopleth (e.g., we checked whether the average $\mathrm{MCP}_{100}$ was significantly different if calculated using a subset of 1 location/day, 3 locations/day, and 12 locations/ day). We performed post hoc comparisons using Tukey's honestly significant difference (HSD) test. $P$-values lower than 0.05 were considered significant.

\section{Results}

The estimates of the Rekambo community home range size from January 2017 to April 2019 varied between 27.64 and $59.03 \mathrm{~km}^{2}$ depending on the estimator and isopleth considered (see isopleths 100-95\% in Table 1). Home range size estimates of the same isopleth differed from 0.01 to $10.48 \mathrm{~km}^{2}$ between estimators. MCP included more areas without relocations than KDE (see AUC values in Table 1). KDE displayed slightly lower AUC than BRB. Relocation subsampling had a significant effect on the areas estimated. The lower the number of relocations, the lower the MCP estimate, while KDE estimates increased with fewer relocations (see Table 2).

Table $2 \mathrm{MCP}_{100}, \mathrm{MCP}_{50}, \mathrm{KDE}_{95}$, and $\mathrm{KDE}_{50}$ of the Rekambo community obtained with different relocation subsampling schemes

\begin{tabular}{llllr}
\hline $\begin{array}{l}\text { Reloca- } \\
\text { tions/day }\end{array}$ & \multicolumn{1}{l}{$\mathrm{km}^{2}$} & & & \\
\cline { 2 - 5 } & $\mathrm{MCP}_{100}$ & $\mathrm{MCP}_{50}$ & $\mathrm{KDE}_{95}$ & \multicolumn{1}{c}{$\mathrm{KDE}_{50}$} \\
\hline 1 & $40.87 \pm 1.91$ & $8.03 \pm 0.44$ & $36.95 \pm 0.75$ & $9.2 \pm 0.40$ \\
3 & $46.52 \pm 1.66$ & $8.62 \pm 0.29$ & $34.70 \pm 0.17$ & $8.56 \pm 0.15$ \\
12 & $52.2 \pm 1.77$ & $8.81 \pm 0.13$ & $33.41 \pm 0.23$ & $8.02 \pm 0.05$ \\
\hline
\end{tabular}

The total number of sampling days between January 2017 and April 2019 was 640. Each subsampling scheme was performed 10 times. Values are mean \pm SD
Table 1 Home range areas $\left(\mathrm{km}^{2}\right)$ by isopleth $(\%)$ and area under the curve (AUC) calculated for the Rekambo community by minimum convex polygon, kernel density estimation, and biased randombridges

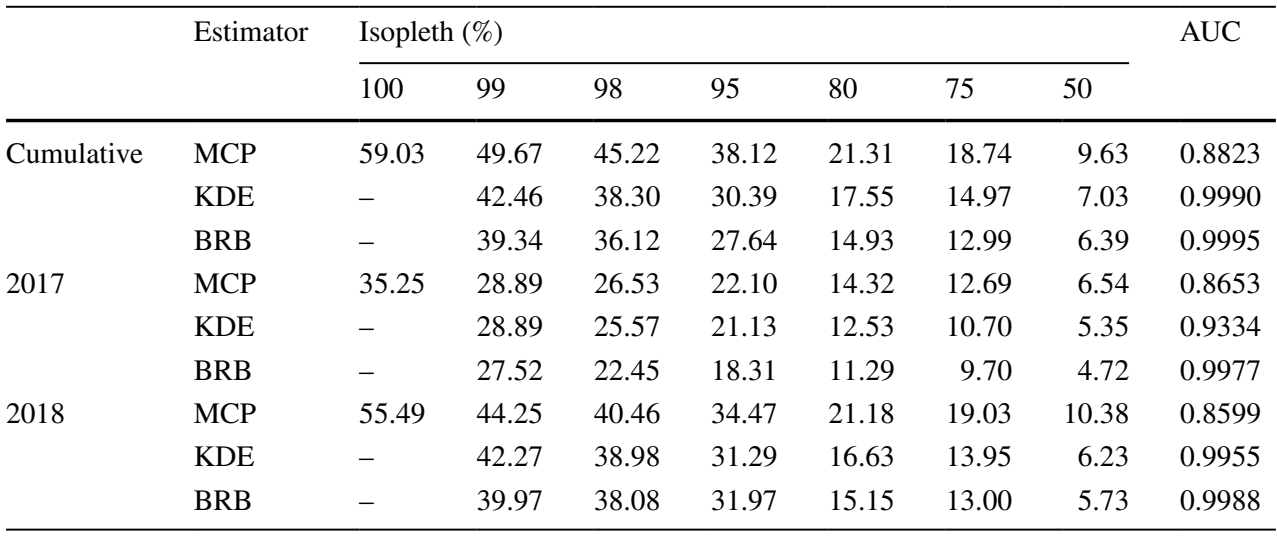

Cumulative: January 2017-April 2019, 670,616 relocations collected over 640 days and $5691 \mathrm{~h}$ of observation. 2017: 205,545 relocations collected over 259 days and $2348 \mathrm{~h}$ of observation. 2018: 340,263 relocations were collected for 277 days and $2793 \mathrm{~h}$ of observation. AUC values can range from 0.5 to 1 . The closer AUC values are to 1, the closer is the agreement between the estimated home range and the relocations (Cumming and Cornélis 2012). AUC are estimated once per full home range volume rather than per isopleth 


\section{Home range analysis}

The results showed that the Rekambo community home range and core area estimates varied depending on the estimator employed and the period considered (see Table 1). MCP consistently produced the largest estimates for all isopleths. KDE estimates were larger than BRB ones for the cumulative and 2018 estimates but not for 2017 . MCP displayed the lowest AUC values, followed by KDE and BRB (see Table 1). Cumulative estimates, meaning estimates calculated combining all data between January 2017 and April 2019, were larger than 2017 estimates for all three methods. Cumulative estimates were larger than 2018 estimates for MCP and KDE, but the opposite was true for BRB (see Table 1).

When focusing on the maximum common isopleth (see 99\%, Fig. 2D), $\mathrm{MCP}_{99}$ encompasses $\mathrm{KDE}_{99}$ and $\mathrm{BRB}_{99}$, except for some areas close to the coast. $\mathrm{MCP}_{99}$ is unique in including the research camp within the Rekambo home range, while $\mathrm{KDE}_{99}$ overlays with the sea. Core area isopleths (75\% and 50\%) fell mostly in the center of the home range taking the $100 \% \mathrm{MCP}$ as a reference. $\mathrm{KDE}$ and $\mathrm{BRB}$ displayed core area patches on the coastal forest (between the savannah and the sea, see Fig. 2E and F), but their areas were larger in KDE than in BRB. Several coastal forest patches that remain in $\mathrm{KDE}_{50}$ disappear in $\mathrm{BRB}_{50}$ (see Fig. 2F). The $50 \%$ isopleth of KDE and BRB is extended towards the edge of the swamp at the northeast of the center, outside the $\mathrm{MCP}_{50}$ (see Fig. 2F). In comparison, $\mathrm{MCP}_{50}$ encompassed parts of the savannah and left out the high-use patches from the coastal forest and the edge of the northeastern swamp.

\section{Recalculating MCP and KDE under different relocation subsampling regimes}

Subsampling the relocations to obtain 1,3 , and 12 per observation day had significant effects on the size of the isopleths estimated by both $\mathrm{MCP}$ and $\mathrm{KDE}\left(\mathrm{MCP}_{100}\right.$ : $F(2,7)=101.4, p<0.001 ; \mathrm{MCP}_{50}: F(2,27)=17.13$; $p<0.001 ; \mathrm{KDE}_{95}: F(2,27)=147.8, p<0.001 ; \mathrm{KDE}_{50}$ : $F(2,27)=56.74, p<0.001)$. The larger the number of relocations per observation day, the larger the area estimated by MCP isopleths, except the core area estimated with 3 and 12 relocations per day, which were not significantly different from each other (see Table 2, all Tukey tests $p<0.001$, except for $\mathrm{MCP}_{100(3 \text { relocations/day) }}$

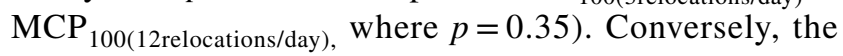
smaller the number of relocations per observation day, the larger the area estimated by KDE isopleths (see Table 2, Tukey tests $p<0.001$ ). The difference between the cumulative $\mathrm{MCP}_{100}$ calculated with all data (see Table 1) and the
$\mathrm{MCP}_{100}$ estimated with one relocation per observation day, (see Table 2) was $18.16 \mathrm{~km}^{2}$. The difference between the cumulative $\mathrm{KDE}_{95}$ calculated with all data (see Table 1), and the $\mathrm{KDE}_{95}$ estimated with one relocation per observation day (see Table 2), was $6.56 \mathrm{~km}^{2}$.

\section{Discussion}

Here, we used three different estimators and different sampling procedures to assess the home range size of a community of central chimpanzees living in a mosaic of different habitat types. We provide the first home range size assessment of the Rekambo community after the habituation of most of its members. Overall, our data showed that the estimated home range size of Rekambo between January 2017 and April 2019 (i.e., cumulative estimate) was $39.34-49.67 \mathrm{~km}^{2}$ when focusing on the largest common isopleth of the three estimators (i.e., 99\%). The annual estimates tended to be smaller than the cumulative estimate. The evaluation of the estimators indicated that BRB performed slightly better than KDE, and both were more accurate than MCP as measured by AUC. The subsampling of relocations yielded significant differences in the results, with smaller numbers of relocations per day leading to smaller MCP and larger KDE estimates.

\section{Comparison between different home range estimators}

The Rekambo home range size estimates differed as expected between those produced with MCP, KDE, and BRB (Börger et al. 2006; Amsler 2009). Equivalent isopleths of MCP covered larger areas than those of KDE and BRB (see Table 1). As expected, subsampling significantly affected the areas estimated by MCP and KDE (Pebsworth et al. 2012; Fieberg and Börger 2012). Smaller numbers of relocations per day produced smaller MCP estimates and larger KDE estimates. KDE and BRB fit the data with comparable accuracy according to AUC values. However, BRB tended to minimally outperform KDE (see Table 1).

Our findings thus strengthen recent notions that, currently, no existing home range estimator is suited for all practical situations and research questions (Fieberg and Börger 2012; Bauder et al. 2015). However, most studies would benefit from estimators that reasonably fit and are suitable for their data (Cumming and Cornélis 2012; Walter et al. 2015). Researchers investigating nonhuman primates often have access to large datasets of highly autocorrelated GPS data (Pebsworth et al. 2012; Cheyne et al. 2019; Albani et al. 2020; Dore et al. 2020). Using such a dataset, we showed that KDE and BRB produced estimates 
Fig. 2 Maps of the cumulative Rekambo home range calculated using three different techniques: minimum convex polygon (MCP), kernel density estimation (KDE), and biased random bridges (BRB). A-C show all the isopleths calculated with each technique in grayscale, where the darkest is $99 \%$ and the lightest $50 \%$. The $100 \%$ MCP is depicted in turquoise. D-F compare equivalent isopleths of the three techniques. MCP in green, $\mathrm{KDE}$ in black, and BRB in blue. Background colors depict the different ecosystems: savannah, beach, swamp, sea, and forest. The * shows the location of the Ozouga research camp. Data used were 670,616 relocations collected over 640 days and $5691 \mathrm{~h}$ of observation between January 2017 and April 2019.

The figure was created using $\mathrm{R}$ (v. 4.0.2, R Core Team 2020)

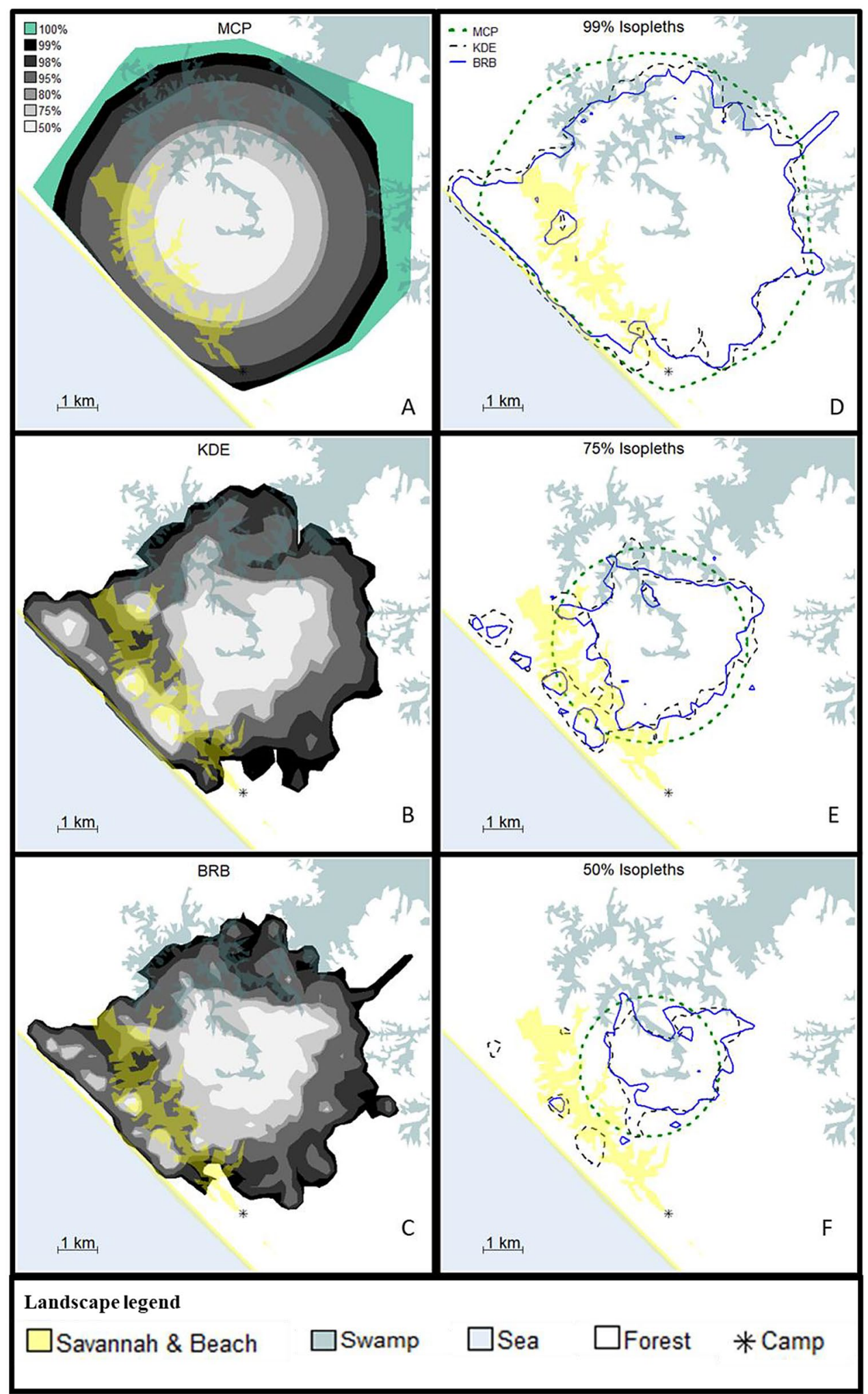

similar to each other in terms of isopleth area and shape (see Fig. 2, Table 1, and Figs. S2 and S3 in ESM). However, BRB showed a slightly better fit according to AUC in the three conditions tested (i.e., one cumulative and two annual estimations). BRB was developed for datasets like the one we had, with highly autocorrelated relocations (Benhamou and Cornélis 2010). Thus, it is not surprising that BRB estimates are closer to the observed relocations 
in this case. However, BRB presents a practical problem when it comes to between-population comparisons. BRB requires selecting more parameters than $\mathrm{KDE}$, which are likely to differ between studies. Similar problems will arise with other new estimators that also account for the temporal component of relocations (e.g., Brownian bridge models, BBMM, Bullard 1998; Horne et al. 2007; dynamic Brownian bridge models, dBBMM, Kranstauber et al. 2012; or autocorrelated kernel density estimation, AKDE, Fleming et al. 2015; Calabrese et al. 2016; Noonan et al. 2019). This may render home range size comparisons between populations even more challenging than they usually are. We exemplify this aspect when comparing the Rekambo home range size to those of other chimpanzee communities. Decisions on what values to choose for the parameters should be made in line with the aims of each study, and it would be unrealistic to expect a consensus across researchers investigating the same species. Therefore, a potential solution to enable comparisons across populations could be to make GPS-relocation information available in databanks, such as movebank.org (Wikelski et al. 2020), allowing researchers to standardize home ranges calculations to compare across sites (Gregory 2017). Researchers specialized in the study of mammal orders such as Rodentia, Carnivora, Cingulata, or Artiodactyla (e.g., Rowcliffe et al. 2012; Calabrese et al. 2016) frequently deposit their GPS-relocation data in databanks. However, this practice is currently uncommon among primatologists (but see Strandburg-Peshkin et al. 2016). Decisions on the availability of location data, however, should consider the potential impacts for the study population (e.g., facilitating poaching).

\section{Comparison with previous estimates of the minimum home range of the Rekambo community}

Previous studies have estimated the minimum home range of the Rekambo community before habituation. For instance, Arandjelovic and colleagues (2011) estimated a minimum home range of $45 \mathrm{~km}^{2}$ for the Rekambo community between 2005 and 2008 using noninvasive genetic monitoring. Head and colleagues (2013), using camera trap data collected for 20 months between 2009 and 2010, estimated a minimum home range of $24.4 \mathrm{~km}^{2}$ for the Rekambo community. Subsequently, during habituation efforts between 2009 and 2011, Head and colleagues (2013) calculated an $\mathrm{MCP}_{100}$ of $36 \mathrm{~km}^{2}$ for this community based on direct observations.

All previous estimates of the minimum home range of the Rekambo community (Arandjelovic et al., 2011; Head et al. 2013) were smaller than our cumulative estimate (i.e., $\mathrm{MCP}_{100}^{2017-2019}: 59.03 \mathrm{~km}^{2}$ ). However, we argue that the actual home range of the community was larger in previous years than in our study period.

First, rarely used areas are unlikely to be represented in an $\mathrm{MCP}_{100}$ drawn using data from noninvasive genetic monitoring due to the low probability of finding samples in areas that are not frequently visited by the study subjects (Granjon et al. 2017; Arandjelovic and Vigilant 2018). In contrast, our $\mathrm{MCP}_{100}^{2017-2019}$ included one-time forays, which significantly increased the total estimate (e.g., compare $\mathrm{MCP}_{100}^{2017-2019}$ and $\mathrm{MCP}_{99}^{2017-2019}$ in Table 1 and Fig. 2A). Second, Arandjelovic and colleagues (2011) found samples belonging to the Rekambo community males $1-2 \mathrm{~km}$ to the north and south of the limits of our $\mathrm{MCP}_{100}^{2017-2019}$. This finding indicates that the home range was larger in 2005-2008 than during our study period.

Third, the study of Head and colleagues (2013) did not monitor some of the northernmost areas that the Rekambo community used in 2005-2008 (Arandjelovic et al. 2011) and during our study period. Chimpanzee community members may, however, have used those areas where no cameras were placed, as they did before and after the study. If this is true, the home range of 2009-2010 would be larger than estimated. Finally, the number of relocations collected during follows greatly exceeds the quantity of equivalent data used by Head and colleagues (2013; 840 GPS points in their study versus 670,616 in ours). Because $\mathrm{MCPs}_{100}$ are very sensitive to sample size (e.g., see Table 2), the difference in data quantity is the most likely explanation for the smaller home range size estimate for 2009-2011 in comparison to our 2017-2019 estimate.

Further evidence suggesting that the Rekambo home range might have been larger in the past is the observation of fewer males during our study period. Studies at other sites such as Gombe (Tanzania) and Taï (Côte d'Ivoire) showed that home range size is often positively correlated with the number of males in the community (Goodall 1986; Boesch and Boesch-Achermann 2000; Lehmann and Boesch 2003). In 2005-2008, Arandjelovic and colleagues (2011) genotyped a minimum of 21 weaned males in the Rekambo community, while Head and colleagues (2013) assigned at least 16 weaned males using camera trap data from 2009 to 2010. These estimates are higher than the 14-16 weaned males observed in our study period (Martínez-Íñigo et al. 2021). Thus, the Rekambo community may have experienced a home range size reduction over the years, along with a decrease in the number of adult males in the community.

\section{Comparing the Rekambo home range size to the home range of other chimpanzee communities}

Most chimpanzee studies have relied on either MCP or $\mathrm{KDE}$ to calculate the home range of their community (see 
Table S1 in ESM). However, studies vary in the amount of data used, the time frame included, how presence data were collected, whether deep incursions were excluded or, in the case of KDE, in the parameters used (see Table S1 in ESM for references). Home range size estimates can change an order of magnitude or more, depending on the estimator employed, the time frame considered, and the number of relocations per day used to produce the estimation (see Tables 1, 2; Grueter et al. 2009; Pebsworth et al. 2012). Thus, it is essential to keep these limitations in mind when comparing home range sizes across studies and communities.

The Rekambo community, which inhabits a forest mosaic, shows a home range size intermediate between forest chimpanzee sites and savannah sites (see Table S1 in ESM for a home range size comparison across 34 chimpanzee communities). We argue that the large size of the home range is likely produced by a combination of factors: the presence of savannah within the home range, interspecific competition, and intercommunity interactions.

Looking at the maximum estimates for each chimpanzee community (see Table S1 in ESM), the Rekambo community has the largest home range after Ugalla (Tanzania, 400-500 km²), Mt. Assirik (Senegal, 278-333 km²), Kasakati L (Tanzania, $124 \mathrm{~km}^{2}$ ), Kasakati Z (Tanzania, 122 $\mathrm{km}^{2}$ ), Fongoli (Senegal, $110.39 \mathrm{~km}^{2}$ ), and Mayebe (Rwanda; $60.98 \mathrm{~km}^{2}$ ) (see Table S1 in ESM for references). Mayebe dwells in a montane forest, a habitat which tends to have lower food availability than lowland forests (Green et al. 2020b). All other communities inhabit dry habitats. Dry habitats tend to have low food availability (Dunbar 1988; Janson and Chapman 1999; Hunt and McGrew 2002) and low population density (Wilson et al. 2014), and are both associated with large home range sizes (Maruhashi 1998; South 1999; Campos et al. 2014). However, Loango has one of the highest annual rainfalls registered for chimpanzee study sites, including those in rainforests (Wessling et al. 2018). Therefore, habitat dryness is unlikely to be the reason why the Rekambo home range is larger than those reported for other forest-dwelling communities of similar size such as Sonso (6.78-9.68 km², 38-56 individuals) or Kanyawara (37.8-41.4 km²; 43-51 individuals) both from Uganda (see Table S1 in ESM for references).

The large home range size of the Rekambo community may be due to the National Park's unique habitat mosaic which includes savannah, a habitat that is poor in food resources for chimpanzees. The Rekambo chimpanzees heavily use the bordering areas of the savannah patches in specific periods (see Fig. 2), such as the Sacoglottis gabonensis fruiting season. However, the savannah itself only provides relatively low amounts of other fruit sources, such as Chrysobalanus icaco (Loango Chimpanzee Project, unpublished data). Thus, the community mostly uses the savannah to traverse between the mature forest and the coastal forest. Hence, although the savannah adds a crucial part to the overall home range size, it is not an important contributor to chimpanzees' food resources. It, thereby, may reduce the average food density per square kilometer, contributing to the large size of the home range and the low population density.

A second factor contributing to the large home range size of the Rekambo community is intense interspecific competition for food resources. Loango National Park shelters forest elephants and western lowland gorillas in addition to chimpanzees. Their diets overlap considerably in Loango (Head et al. 2012), as they do in other central African sites such as Kahuzi-Biega, in the Democratic Republic of the Congo (Kaboko community in Table S1 in ESM), and Goualougo Triangle in Nouabale-Ndoki National Park, Republic of the Congo (Moto community in Table S1 in ESM) (Yumoto et al. 1995; Blake 2002; Morgan and Sanz 2006). Elephants and gorillas could be lowering the density of food available to chimpanzees, resulting in an increase of the home range size of the Rekambo community. However, so far, relatively little is known about interactions and food competition of the Rekambo chimpanzees with gorillas and elephants. Head and colleagues (2011) found that chimpanzee and gorilla diets at Loango overlapped between 0.3 and $69 \%$ in relation to the season but not to fruit availability. Southern and colleagues (2021, in press) recently reported two lethal coalitional attacks of individuals of the Rekambo community against gorillas. They argued that additional observations in combination with isochronous assessments of fruit availability and dietary overlap are crucially needed to differentiate whether the attacks represent opportunistic hunting or species competition in times of food scarcity. In addition, elephants competitively exclude chimpanzees when fruits are scarce (Head et al. 2012) and compete with them for honey (Estienne et al. 2017a). Elephants are more abundant in Loango National Park than in either Kahuzi-Biega or Nouabale-Ndoki National Park (Hall et al. 1997; Stokes et al. 2010; Head et al. 2012). Thus, interspecies competition between elephants and chimpanzees may also have a crucial impact upon home range size at Loango.

Finally, intercommunity interactions might be a third factor contributing to the size of the Rekambo community home range. At Taï, low intercommunity encounter rates correlate with larger home ranges (Boesch and Boesch-Achermann 2000; Lehmann and Boesch 2003; Lemoine et al. 2020). Both, low intercommunity encounter rates and large home ranges, seem to be a consequence of a large community size relative to neighboring communities (Lemoine et al. 2020). Previous studies estimated that at least three chimpanzee communities surrounded Rekambo, which was the largest community of the study area in 2005-2011 (Arandjelovic et al. 2011; Head et al. 2013). To date, individuals of the 
Rekambo community encounter individuals of neighboring communities less often than many other chimpanzee communities elsewhere (Martínez-Íñigo et al. 2021). The combination of large home range and community size, and low intergroup encounter rate, suggests that Rekambo benefits from a competitive advantage over neighboring communities. In fact, combined evidence suggests that the Rekambo community expanded their range towards the south, beyond the research camp (see Fig. 2), after killing several individuals of the community that ranged there between 2005 and 2007 (Boesch et al. 2007; Arandjelovic et al. 2011). Consequently, a competitive advantage over their neighboring communities would be a factor explaining the Rekambo community's large home range size. Nonetheless, contrary to this interpretation, neighboring communities seem to exert great pressure over Rekambo, entering within their core area, where intergroup encounters are more frequent than in the periphery (Martínez-Íñigo et al. 2021). At Taï, communities experiencing incursions into their core areas are less numerous than their neighbors, and their home ranges are smaller (Lemoine et al. 2020). Hence, it may be possible that the Rekambo community had a numerical advantage that allowed them to maintain a large home range in the past (i.e., 2005-2011). However, between 2005 and 2019, the number of adult males, which are the most active age-sex class during intercommunity encounters (MartínezÍnigo et al. 2021), decreased in the Rekambo community (Arandjelovic et al. 2011; Head et al. 2013; Estienne et al. $2017 \mathrm{~b}$, present study). As a consequence, the community might have lost their competitive advantage (Boesch et al. 2007; Arandjelovic et al. 2011), encouraging neighbors to enter the home range of the Rekambo community. If this is the case, we may expect a shrinkage in the size of the home range of the Rekambo community along with an increased rate of intercommunity encounters in the future.

\section{Conclusions and future research}

Currently, there are many different home range estimators available to researchers. MCP and KDE have long been used, and are useful for comparison across studies. However, researchers compiling highly autocorrelated data from GPS devices would obtain more accurate estimates using new-generation estimators designed explicitly for such data, like BRB.

The Rekambo community appears to have one of the largest home ranges among chimpanzees living in habitats other than savannah-woodland, regardless of the estimator or amount of data used to calculate it. The location of its home range has remained constant over the last decade, although some evidence suggests that its size might have decreased.
The large size of the home range could be due to several factors combined, such as the presence of a considerable amount of savannah habitat within the range, interspecies competition with elephants and gorillas, and intercommunity relationships. Future studies on food availability and distribution at the site, as well as further research into interspecies competition between sympatric apes and other large mammals, are crucial to understanding their impact on home range size.

Supplementary Information The online version contains supplementary material available at https://doi.org/10.1007/s10329-021-00927-5.

Acknowledgements We are grateful to the Agence Nationale des Parcs Nationaux, and the Centre National de la Recherche Scientifique et Technique of Gabon for their collaboration and permission to conduct research in Loango National Park. We are indebted to C. Boesch for his steady support and inspiring discussions. We also especially thank R. Mundry for his help with the statistical analysis, and S. Lemoine for constructive exchanges. We are thankful to M. Arandjelovic for her helpful comments and editing the manuscript. We are indebted to $\mathrm{N}$. Balduccio, J. C. Bitoy, S. Bunel, A. Ede, J. Ekika, S. Iadou, G. Kombe, J. Kombe, J. C. Mabioko, F. Makaya, M. Makosso, A. Mascaro, M. Massande, A. Mitifiot, R. Mokambe, P. Mondjo, U. Bora Moussouami, E. Ngabe, Y. Nkoma, P. Nzambe, J. E. Nzengue, L. Southern, K. Stewart, E. Theleste, R. Violleau, and many others for their help with the data collection and support in the forest. A special thanks to C. Igoumounamendet and S. Emane for their invaluable help at and around the Ozouga Camp.

Author contributions LMI, TD, and PB designed the study. PB, HK, and LMI collected and curated the data and performed the analyses. LMI and PB wrote the first draft of the manuscript, LMI, SP, and TD finalized it. All authors approved the final manuscript.

Funding Open Access funding enabled and organized by Projekt DEAL. This study was supported by the Max Planck Society and an ERC Consolidator Grant (772000; TurnTaking) by the EU to SP.

Data deposition information Travel routes are available through Movebank (https://www.movebank.org/cms/webapp?gwt_fragment=page= studies,path=study1280077382; Movebank ID: 1280077382).

Code availability Electronic Supplementary Material.

\section{Declarations}

Conflict of interest The authors declare that they have no conflicts of interest.

Ethics approval Our study was purely observational and noninvasive. Researchers followed a strict hygiene protocol (Gilardi et al. 2015). Researchers quarantine for 5 days before following the chimpanzees. During follows, researchers disinfect their hands before entering the forest, wear face masks, and keep a minimum distance of $8 \mathrm{~m}$ between themselves and the chimpanzees, to avoid disease transmission from humans to chimpanzees and to not disturb the natural behavior of the observed individuals. Research protocols adhered to the legal requirements of Gabon and followed the recommendations of the Animals (Scientific Procedures) Act 1986, as published by the government of the United Kingdom. The research also followed the principles of 
"Ethical Treatment of Non-Human Primates" as stated by the American Society of Primatologists. The Agence Nationale des Parcs Nationaux, and the Centre National de la Recherche Scientifique et Technique of Gabon, Libreville, Gabon granted permission to carry out research at Loango National Park.

Open Access This article is licensed under a Creative Commons Attribution 4.0 International License, which permits use, sharing, adaptation, distribution and reproduction in any medium or format, as long as you give appropriate credit to the original author(s) and the source, provide a link to the Creative Commons licence, and indicate if changes were made. The images or other third party material in this article are included in the article's Creative Commons licence, unless indicated otherwise in a credit line to the material. If material is not included in the article's Creative Commons licence and your intended use is not permitted by statutory regulation or exceeds the permitted use, you will need to obtain permission directly from the copyright holder. To view a copy of this licence, visit http://creativecommons.org/licenses/by/4.0/.

\section{References}

Abwe EE (2018) Linking behavioral diversity with genetic and ecological variation in the Nigeria-Cameroon chimpanzee (Pan troglodytes ellioti). $\mathrm{PhD}$ Thesis, Drexel University

Albani A, Cutini M, Germani L et al (2020) Activity budget, home range, and habitat use of moor macaques (Macaca maura) in the karst forest of South Sulawesi Indonesia. Primates 61:673-684. https://doi.org/10.1007/s10329-020-00811-8

Amsler S (2009) Ranging behavior and territoriality in chimpanzees at Ngogo, Kibale National Park, Uganda. PhD Dissertation, University of Michigan

Arandjelovic M, Vigilant L (2018) Non-invasive genetic censusing and monitoring of primate populations. Am J Primatol 80:1-14. https://doi.org/10.1002/ajp.22743

Arandjelovic M, Head J, Rabanal LI et al (2011) Non-invasive genetic monitoring of wild central chimpanzees. PLoS ONE 6(3):e14761. https://doi.org/10.1371/journal.pone.0014761

Bauder JM, Breininger DR, Bolt MR et al (2015) The role of the bandwidth matrix in influencing kernel home range estimates for snakes using VHF telemetry data. Wildl Res 42:437-453. https:// doi.org/10.1071/WR14233

Benhamou S, Cornélis D (2010) Incorporating movement behavior and barriers to improve kernel home range space use estimates. J Wildl Manag 74:1353-1360. https://doi.org/10.2193/2009-441

Blake S (2002) The ecology of forest elephant distribution and its implications for conservation. $\mathrm{PhD}$ Dissertation, University of Edinburgh

Boesch C, Boesch-Achermann H (2000) The chimpanzees of the Tai forest: behavioural ecology and evolution. Oxford University Press, New York

Boesch C, Head J, Tagg N et al (2007) Fatal chimpanzee attack in Loango National Park, Gabon. Int J Primatol 28:1025-1034. https://doi.org/10.1007/s10764-007-9201-1

Börger L, Franconi N, De Michele G et al (2006) Effects of sampling regime on the mean and variance of home range size estimates. $\mathbf{J}$ Anim Ecol 75:1393-1405. https://doi.org/10.1111/j.1365-2656. 2006.01164.x

Boyer Ontl KM (2017) Chimpanzees in the Island of Gold: impacts of artisanal small-scale gold mining on chimpanzees (Pan troglodytes verus) in Fongoli, Senegal. PhD Dissertation, Iowa State University
Bullard F (1998) Estimating the home range of an animal: a Brownian bridge approach. MSc Dissertation, University of North Carolina at Chapel Hill

Burt WH (1943) Territoriality and home range concepts as applied to mammals. J Mammal 24:346-352

Calabrese JM, Fleming CH, Gurarie E (2016) Ctmm: an R Package for analyzing animal relocation data as a continuous-time stochastic process. Methods Ecol Evol 7:1124-1132. https://doi.org/10. 1111/2041-210X.12559

Calenge C (2006) The package "adehabitat" for the R software: a tool for the analysis of space and habitat use by animals. Ecol Modell 197:516-519. https://doi.org/10.1016/j.ecolmodel.2006.03.017

Campos FA, Bergstrom ML, Childers A et al (2014) Drivers of home range characteristics across spatiotemporal scales in a Neotropical primate, Cebus capucinus. Anim Behav 91:93-109. https://doi. org/10.1016/j.anbehav.2014.03.007

Cheyne SM, Capilla BR, Abdulaziz K et al (2019) Home range variation and site fidelity of Bornean southern gibbons [Hylobates albibarbis] from 2010-2018. PLoS ONE 14(7):e0217784. https:// doi.org/10.1371/journal.pone.0217784

Cumming GS, Cornélis D (2012) Quantitative comparison and selection of home range metrics for telemetry data. Divers Distrib 18:1057-1065. https://doi.org/10.1111/j.1472-4642.2012.00908.x

Dore KM, Hansen MF, Klegarth AR et al (2020) Review of GPS collar deployments and performance on nonhuman primates. Primates 61(3):373-387. https://doi.org/10.1007/s10329-020-00793-7

Dunbar RIM (1988) Primate social systems. Croom Helm, London

Estienne V, Mundry R, Kühl HS, Boesch C (2017a) Exploitation of underground bee nests by three sympatric consumers in Loango National Park, Gabon. Biotropica 49:101-109. https://doi.org/10. 1111/btp.12354

Estienne V, Stephens C, Boesch C (2017b) Extraction of honey from underground bee nests by central African chimpanzees (Pan troglodytes troglodytes) in Loango National Park, Gabon: techniques and individual differences. Am J Primatol 79:e22672

Fauvelle C, Diepstraten R, Jessen T (2017) A meta-analysis of home range studies in the context of trophic levels: implications for policy-based conservation. PLoS ONE 12(3):e0173361. https:// doi.org/10.1371/journal.pone.0173361

Fawcett KA (2000) Female relationships and food availability in a forest community of chimpanzees. PhD Dissertation, University of Edinburgh

Fieberg J, Börger L (2012) Could you please phrase "home range" as a question? J Mammal 93:890-902. https://doi.org/10.1644/ 11-mamm-s-172.1

Fleming CH, Fagan WF, Mueller T et al (2015) Rigorous home range estimation with movement data: a new autocorrelated kernel density estimator. Ecology 96:1182-1188. https://doi.org/10. 1890/14-2010.1

Gilardi K, Gillespie T, Leendertz et al. (2015) Best practice guidelines for health monitoring and disease control in great ape populations. IUCN SSC Primate Specialist Group. Gland, Switzerland

Goodall J (1986) The chimpanzees of Gombe: patterns of behaviour. Harvard University Press, Cambridge

Granjon AC, Rowney C, Vigilant L, Langergraber KE (2017) Evaluating genetic capture-recapture using a chimpanzee population of known size. J Wildl Manag 81:279-288. https://doi.org/10.1002/ jwmg. 21190

Green SJ, Boruff BJ, Grueter CC (2020a) From ridge tops to ravines: landscape drivers of chimpanzee ranging patterns. Anim Behav 163:51-60. https://doi.org/10.1016/j.anbehav.2020.02.016

Green SJ, Boruff BJ, Niyigaba P, Ndikubwimana I, Grueter CC (2020b) Chimpanzee ranging responses to fruit availability in a high-elevation environment. Am J Primatol 82:e23119. https://doi.org/ 10.1002/ajp.23119 
Gregory T (2017) Home range estimation. In: Fuentes A (ed) The international encyclopedia of primatology. Wiley, Hoboken, pp 1-4

Grueter CC, Li D, Ren B, Wei F (2009) Choice of analytical method can have dramatic effects on primate home range estimates. Primates 50:81-84. https://doi.org/10.1007/s10329-008-0113-2

Hall JS, Inogwabini BI, Williamson EA et al (1997) A survey of elephants (Loxodonta africana) in the Kahuzi-Biega National Park lowland sector and adjacent forest in eastern Zaire. Afr J Ecol 35:213-223. https://doi.org/10.1111/j.1365-2028.1997. 088-89088.x

Head JS, Boesch C, Makaga L, Robbins MM (2011) Sympatric chimpanzees (Pan troglodytes troglodytes) and gorillas (Gorilla gorilla gorilla) in Loango National Park, Gabon: dietary composition, seasonality, and intersite comparisons. Int J Primatol 32:755-775. https://doi.org/10.1007/s10764-011-9499-6

Head JS, Robbins MM, Mundry R et al (2012) Remote video-camera traps measure habitat use and competitive exclusion among sympatric chimpanzee, gorilla and elephant in Loango National Park, Gabon. J Trop Ecol 28:571-583. https://doi.org/10.1017/S0266 467412000612

Head JS, Boesch C, Robbins MM et al (2013) Effective sociodemographic population assessment of elusive species in ecology and conservation management. Ecol Evol 3:2903-2916. https://doi. org/10.1002/ece 3.670

Herbinger I, Boesch C, Rothe H (2001) Territory characteristics among three neighboring chimpanzee communities in the Taï National Park, Côte d'Ivoire. Int J Primatol 22:143-167. https://doi.org/10. 1023/A:1005663212997

Horne JS, Garton EO, Krone SM, Lewis JS (2007) Analyzing animal movements using Brownian bridges. Ecology 88:2354-2363. https://doi.org/10.1890/06-0957.1

Humle T, Maisels F, Oates JF et al. (2016) Pan troglodytes (errata version published in 2018). The IUCN Red List of Threatened Species 2016: e.T15933A129038584. https://doi.org/10.2305/IUCN. UK.2016-2.RLTS.T15933A17964454.en. Accessed 20 Sep 2020

Hunt KD, McGrew WC (2002) Chimpanzees in the dry habitats of Assirik, Senegal and Semliki Wildlife Reserve, Uganda. In: Boesch C, Hohmann G, Marchant L (eds) Behavioural diversity in chimpanzees and bonobos. Cambridge University Press, Cambridge, pp 35-51

Janson CH, Chapman CA (1999) Resources and primate community structure. In: Fleagle JG, Janson C, Reed KE (eds) Primate Communities. Cambridge University Press, Cambridge, pp 237-267

Kouakou CY, Boesch C, Kuehl HS (2011) Identifying hotspots of chimpanzee group activity from transect surveys in Taï National Park, Côte d'Ivoire. J Trop Ecol 27:621-630. https://doi.org/10. 1017/S0266467411000423

Kranstauber B, Kays R, Lapoint SD et al (2012) A dynamic Brownian bridge movement model to estimate utilization distributions for heterogeneous animal movement. J Anim Ecol 81:738-746. https://doi.org/10.1111/j.1365-2656.2012.01955.x

Laver PN, Kelly MJ (2008) A critical review of home range studies. J Wildl Manag 72:290-298. https://doi.org/10.2193/2005-589

Lehmann J, Boesch C (2003) Social influences on ranging patterns among chimpanzees (Pan troglodytes verus) in the Taï National Park, Côte d'Ivoire. Behav Ecol 14:642-649. https://doi.org/10. 1093/beheco/arg047

Lemoine S, Boesch C, Preis A et al (2020) Group dominance increases territory size and reduces neighbour pressure in wild chimpanzees. R Soc Open Sci 7:200577. https://doi.org/10.1098/rsos. 200577

Map Maker Ltd (2007) Map Library. http://www.maplibrary.org/. Accessed 06 Jul 2020

Martínez-Íñigo L, Baas P, Klein H et al (2021) Intercommunity interactions and killings in central chimpanzees (Pan troglodytes troglodytes) from Loango National Park, Gabon. Primates, pp 1-14. https://doi.org/10.1007/s10329-021-00921-x

Maruhashi T (1998) Home range structure and inter-group competition for land of Japanese macaques in evergreen and deciduous forests. Primates 39(3):291-301

Mitani JC, Watts DP, Amsler SJ (2010) Lethal intergroup aggression leads to territorial expansion in wild chimpanzees. Curr Biol 20:507-508. https://doi.org/10.1016/j.cub.2010.04.021

Mohr CO (1947) Table of equivalent populations of North American small mammals. Am Midl Nat 37:223-249

Moore JF, Mulindahabi F, Gatorano G et al (2018) Shifting through the forest: home range, movement patterns, and diet of the eastern chimpanzee (Pan troglodytes schweinfurthii) in Nyungwe National Park Rwanda. Am J Primatol 80(8):e22897. https://doi. org/10.1002/ajp.22897

Morgan D, Sanz C (2006) Chimpanzee feeding ecology and comparisons with sympatric gorillas in the Goualougo Triangle, Republic of Congo. In: Hohmann G, Robbins M, Boesch C (eds) Feeding ecology in apes and other primates: ecological, physical, and behavioral aspects. Cambridge University Press, Cambridge, pp $97-122$

Morgan D, Sanz C, Onononga JR, Strindberg S (2006) Ape abundance and habitat use in the Goualougo Triangle Republic of Congo. Int J Primatol 27(1):147-149. https://doi.org/10.1007/ s10764-005-9013-0

Nakamura M, Corp N, Fujimoto M et al (2013) Ranging behavior of Mahale chimpanzees: a 16 year study. Primates 54:171-182. https://doi.org/10.1007/s10329-012-0337-z

Newton-Fisher NE (2003) The home range of the Sonso community of chimpanzees from the Budongo Forest, Uganda. Afr J Ecol 41:150-156. https://doi.org/10.1046/j.1365-2028.2003.00408.x

Nishida T (1979) The social structure of chimpanzees of the Mahale Mountains. In: Hamburg DA, McCown ER (eds) The great apes. Benjamin/Cummings, Menlo Park, pp 73-121

Nishida T, Hiraiwa-Hasegawa M, Hasegawa T, Takahata Y (1985) Group extinction and female transfer in wild chimpanzees in the Mahale National Park, Tanzania. Z Tierpsychol 67:284-301

Noonan MJ, Tucker MA, Fleming CH et al (2019) A comprehensive analysis of autocorrelation and bias in home range estimation. Ecol Monogr 89(2):e01344. https://doi.org/10.1002/ecm.1344

Pebsworth PA, Morgan HR, Huffman MA (2012) Evaluating home range techniques: use of global positioning system (GPS) collar data from chacma baboons. Primates 53:345-355. https://doi.org/ 10.1007/s10329-012-0307-5

Powell RA, Mitchell MS (2012) What is a home range? J Mammal 93:948-958. https://doi.org/10.1644/11-mamm-s-177.1

$\mathrm{R}$ Core Team (2020) R: a language and environment for statistical computing. R Foundation for Statistical Computing, Vienna

Rowcliffe JM, Carbone C, Kays R et al (2012) Bias in estimating animal travel distance: the effect of sampling frequency. Methods Ecol Evol 3:653-662. https://doi.org/10.1111/j.2041-210X.2012. 00197.x

South A (1999) Extrapolating from individual movement behaviour to population spacing patterns in a ranging mammal. Ecol Modell 117:343-360. https://doi.org/10.1016/S0304-3800(99)00015-0

Southern LM, Deschner T, Pika S (2021) Lethal coalitionary interactions between chimpanzees (Pan troglodytes troglodytes) and gorillas (Gorilla gorilla gorilla) in the wild (Scientific Reports, in press)

Stokes EJ, Strindberg S, Bakabana PC et al (2010) Monitoring great ape and elephant abundance at large spatial scales: measuring effectiveness of a conservation landscape. PLoS ONE 5(4):e10294. https://doi.org/10.1371/journal.pone.0010294

Strandburg-Peshkin A, Farine DR, Couzin ID, Crofoot MC (2016) Shared decision-making drives collective movement in wild 
baboons. Science 348(6241):1358-1361. https://doi.org/10.1126/ science.aaa5099

Tuszynski J (2020) caTools: Tools: moving window statistics, GIF, Base64, ROC AUC, etc. R package version 1.18.0

UNEP-WCMC, IUCN (2020) Protected planet: Loango (WDPA ID 303874). In: The World Database on Protected Areas (WDPA)/ The Global Database on Protected Areas Management Effectiveness (GD-PAME)]. https://www.protectedplanet.net/loango-natio nal-park Accessed 06 Jul 2020

Walter DW, Fischer JW, Baruch-Mordo S, VerCauteren KC (2011) What is the proper method to delineate home range of an animal using 'today's advanced GPS telemetry systems: the initial step. In: Krejcar O (ed) Modern telemetry. InTech, London, pp 249-268

Walter WD, Onorato DP, Fischer JW (2015) Is there a single best estimator? Selection of home range estimators using areaunder-the-curve. Mov Ecol 3:1-11. https://doi.org/10.1186/ s40462-015-0039-4

Watts DP, Mitani JC (2015) Hunting and prey switching by chimpanzees (Pan troglodytes schweinfurthii) at Ngogo. Int J Primatol 36:728-748. https://doi.org/10.1007/s10764-015-9851-3

Wessling EG, Deschner T, Mundry R et al (2018) Seasonal variation in physiology challenges the notion of Chimpanzees (Pan troglodytes verus) as a forest-adapted species. Front Ecol Evol 6:60. https://doi.org/10.3389/fevo.2018.00060

Wikelski M, Davidson S, Kays R (2020) Movebank: archive and sharing of animal movement data. Hosted by the Max Planck Institute of Animal Behavior. https://www.movebank.org. Accessed 7 May 2020
Williams JM, Pusey AE, Carlis JV et al (2002) Female competition and male territorial behaviour influence female chimpanzees' ranging patterns. Anim Behav 63:347-360. https://doi.org/10.1006/anbe. 2001.1916

Wilson ML, Hauser MD, Wrangham RW (2001) Does participation in intergroup conflict depend on numerical assessment, range location, or rank for wild chimpanzees? Anim Behav 61:1203-1216. https://doi.org/10.1006/anbe.2000.1706

Wilson ML, Kahlenberg SM, Wells M, Wrangham RW (2012) Ecological and social factors affect the occurrence and outcomes of intergroup encounters in chimpanzees. Anim Behav 83:277-291. https://doi.org/10.1016/j.anbehav.2011.11.004

Wilson ML, Boesch C, Fruth B et al (2014) Lethal aggression in Pan is better explained by adaptive strategies than human impacts. Nature 513:414-417. https://doi.org/10.1038/nature13727

Worton BJ (1987) A review of models of home range for animal movement. Ecol Modell 38:277-298. https://doi.org/10.1016/03043800(87)90101-3

Yumoto T, Maruhashi T, Yamagiwa J, Mwanza N (1995) Seed-dispersal by elephants in a tropical rain forest in Kahuzi-Biega National Park Zaire. Biotropica 27:526. https://doi.org/10.2307/2388968

Publisher's Note Springer Nature remains neutral with regard to jurisdictional claims in published maps and institutional affiliations. 